\title{
LA CUESTIÓN CANARIA ANTE LA ADHESIÓN DE ESPAÑA A LA COMUNIDAD ECONÓMICA EUROPEA (1983-1990)
}

\author{
The Canary Island's issue on the accession of Spain to the European \\ Economic Community (1983-1990)
}

Domingo Gari

Universidad de La Laguna dhayeck@ull.edu.es

Cómo citar este artículo/Citation:

Domingo GARI (2018), "La cuestión canaria ante la adhesión de España a la Comunidad Económica Europea (1983-1990)”, Hispania Nova, 16, págs. 358-393, DOI: https://doi.org/10.20318/hn.2018.4041
Copyright: (c) HISPANIA NOVA es una revista debidamente registrada, con ISSN II38-73I9 y Depósito Legal M 9472-1998. Los textos publicados en esta revista están -si no se indica lo contrario- bajo una licencia Reconocimiento-Sin obras derivadas 3.0 España de Creative Commons. Puede copiarlos, distribuirlos y comunicarlos públicamente siempre que cite su autor y la revista y la institución que los publica y no haga con ellos obras derivadas. La licencia completa se puede consultar en: http://creativecommons.org/licenses/by-nd/3.0/es/deed.es
Resumen: Canarias no tenía claro cómo afrontar la adhesión española a la Comunidad Económica Europea, y los temores y las incertidumbres florecieron en las clases empresariales $y$ en la representación política. El gobierno autónomo estimaba prioritario definir la posición canaria con respecto al tema, y su compromiso se establecía en el sentido de mantener las peculiaridades económicas y fiscales, y así se lo haría saber al gobierno del estado para que éste negociara en esos términos en Bruselas. Canarias estaría en Europa de manera similar a como estaba en España. Esta fue la principal hipótesis para la negociación en la que también se reconocía la mayoría parlamentaria en la Cámara autonómica.

Palabras Clave: Autonomía, Bruselas, protocolo 2, España, Canarias, Europa.
Abstract: It wasn't clear in the Canary Islands how to face the Spanish accession to the European Economic Community, and fears and uncertainties flourished in the business classes and political representation. The autonomous government considered it a priority to define the Canarian position with regard to the theme, and its commitment was established in the sense of maintaining the economic and fiscal peculiarities, and so the state government would be informed so that it negotiated in those terms in Brussels. The Canary Islands would be in Europe in a similar way as it was in Spain. This was the main hypothesis for the negotiation in which the parliamentary majority in the autonomous chamber was also recognized.

Keywords: Autonomy, Brussels, Protocol 2, Spain, Canary Islands, Europe. 


\section{Introducción}

La controversia sobre el Mercado Común Europeo centralizó durante bastante tiempo la actividad parlamentaria y político-social desde el inicio de la autonomía. Canarias no tenía claro cómo afrontar la adhesión española ${ }^{1}$ al MCE, y los temores y las incertidumbres florecieron en las clases empresariales y en la representación política.

Desde la toma de posesión del primer gobierno autónomo la cuestión europea fue objeto de atención prioritaria, aunque Canarias tenía que defender su posición contando con la necesaria intermediación del gobierno del estado, que era a la postre el único sujeto político con soberanía para que las demandas canarias pudiesen ser atendidas en Bruselas. Pero el estado necesitaba a su vez atender las sugerencias o peticiones que le plantease el Parlamento de Canarias, o el gobierno autónomo, tal y como recogía el artículo 45.2 del estatuto de autonomía. En dicho artículo se decía que: "En el caso de una futura vinculación de España a áreas o comunidades económicas supranacionales, en las negociaciones correspondientes se tendrá en cuenta, para su defensa, la peculiaridad que se supone dentro de la comunidad nacional al régimen especial de Canarias". Para algunos expertos "este epígrafe constituye una cláusula de salvaguardia y encierra un importante imperativo jurídico de cara a la negociación de la adhesión española a la Comunidad Europea. Este imperativo jurídico se traduce en la obligatoriedad $<$ de tener en cuenta para su

\footnotetext{
1 Sobre España y la CEE ver Julio CRESPO MAcLENNAN, España en Europa, 1945-2000. Del ostracismo a la modernidad, Madrid, Marcial Pons, 2004. Julio GIL PECHARROMAN, Historia de la integración europea, Madrid, UNED, 2012. Raimundo BASSOLS, España en Europa. Historia de la adhesión a la CE, 1957-85, Madrid, Política Exterior, 1995. Ramón TAMAMES, La Unión Europea, Madrid, Alianza, 1994. Ramón TAMAMES, Guía del MCE. España en la Europa de los doce, Alianza, Madrid, 1986. Pedro MONTES, La integración en Europa: del plan de estabilización a Maastricht, Madrid, Trotta, 1993. Francesc MORATA y Gemma MATEO (eds.), España en Europa, Europa en España (1986-2006), CDOB, Barcelona, 2007. Berta ÁLVAREZ-MIRANDA, El sur de Europa y la adhesión a la Comunidad: Los debates políticos, CIS, Madrid, 1996. VV.AA., España-Europa, Revista Sistema, nº 86-87, Noviembre, 1988.
} 
defensa (...) la peculiaridad (...) del régimen especial de Canarias $>>$ ". Para esta autora, y para otros expertos, se podía entrever la posibilidad "de la presencia de representantes de la Comunidad Autónoma en negociaciones relacionadas con la vinculación de España en áreas supranacionales" ${ }^{3}$. Aunque ello no fue así, el asunto sí tuvo recorrido entre los especialistas del derecho internacional y en algunos grupos políticos, no ciertamente en el gobierno autónomo de entonces ${ }^{4}$.

El debate que se abrió en el Parlamento canario incluía tres opciones por las que podían optar los parlamentarios, y en todas ellas se tenía como idea principal la defensa del Régimen Económico y Fiscal (REF), en torno al cual se estimaba que giraban los interés del archipiélago. Las tres opciones eran la integración, la integración con condiciones específicas y la no integración.

El Parlamento se había configurado con una mayoría relativa del PSOE, que obtuvo 27 diputados sobre un total de 60. Los demás se repartían de la siguiente forma: Coalición Popular (CP) 17; Centro Democrático y Social (CDS) 6; Asamblea Majorera (AM) 3; Unión del Pueblo Canario-Asamblea Canaria (UPC-AC) 2; Agrupación Gomera Independiente (AGI) 2; Agrupación Herreña Independiente (AHI) 1; Coalición Convergencia Nacionalista Canaria (CCNC) 1; Partido Comunista de Canarias (PCC-PCE) 1. Dada esa correlación de fuerzas el PSOE tuvo que obtener apoyo externo para poder formar gobierno, y a dicha tarea se puso manos a la obra para conseguir una mayoría absoluta de cara a la investidura del candidato Jerónimo Saavedra. La investidura se obtuvo con los 27 votos del PSOE, tres de AM y uno de AHI. Nacía así el primer gobierno autónomo en la historia de Canarias.

\footnotetext{
${ }^{2}$ María Asunción ASÍN CABRERA, Islas y Archipiélagos en las Comunidades Europeas, Madrid, Tecnos, 1988, pág. 249.

${ }^{3}$ Ibídem. Ver también Antonio, CARBALLO COTANDA, Canarias, islas francas. Las especialidades económico-fiscales del Archipiélago, Cámara de Comercio de Tenerife, 1970. J. HARDISSON RUMEU, Guillermo NÚÑEZ PÉREZ, "Especialidades económico-fiscales de Canarias" en Geografía de Canarias Tomo VI, Las Palmas de Gran Canaria, Interinsular Canaria, 1985. Alberto GÉNOVA GALVÁN, "EI régimen económico-fiscal canario ante la Constitución de 1978: Análisis jurídico de la Disposición Adicional Tercera" en Revista de Estudios de la Vida Local, n² 218, 1983. F. CLAVIJO HERNÁNDEZ, y A. YANES HERREROS, "La entrada de España en el Mercado Común y la Cláusula Adicional Tercera" en Canarias ante el cambio, Universidad de La Laguna, 1981.

${ }^{4}$ Daniel CERDÁN [ed.], El debate sobre la integración europea, Santa Cruz de Tenerife, Idea, 2009. En este libro están recogidos los cuatro informes fundamentales realizados por distintos expertos.
} 
El compromiso adquirido por los socialistas consistía en impulsar los mecanismos legales e institucionales que desarrollasen la autonomía, una política social que atendiera las altas tasas de paro e impulsara un sistema educativo universal y de calidad. Los socialistas entendían que existía una relación directa entre el bajo nivel educativo y las altas tasas de paro y su objetivo era revertir ambas situaciones. Los efectos de la crisis internacional de 1979 se dejaron sentir en Canarias a comienzo de la década de los ochenta, y tuvieron su influencia más notoria en la pérdida de poder adquisitivo de los salarios, los problemas en el sector pesquero, la alta competencia de los productos importados y el descenso del tráfico de buques. Todo ello hacía que se sintiese la crisis con virulencia, y los datos para la población desempleada así lo reflejaba porque en las oficinas estadísticas se anotaba que un $20 \%$ de la población estaba sin trabajo. A ello se sumó un alto índice de población joven poco cualificada y con serias dificultades para insertarse en el mercado laboral ${ }^{5}$.

El gobierno autónomo de esta primera legislatura tuvo que afrontar como ocupación central el problema de la integración en el MCE. El gobierno de Saavedra estimaba prioritario definir la posición canaria con respecto al MCE, y su compromiso se establecía en el sentido de mantener las peculiaridades económicas y fiscales, y así se lo haría saber al gobierno del estado para que éste negociara en esos términos en Bruselas. Para el gobierno socialista "la respuesta canaria a la adhesión se hará considerando no solo el mantenimiento de nuestra especificidad económica-fiscal sino el coste de la vida y la situación de nuestro mercado de trabajo, bajo el prisma de mantener un régimen económico adecuado a nuestras necesidades y que permita el crecimiento autosostenido y la potenciación de nuestros sectores con posibilidades de futuro"6.

\footnotetext{
${ }^{5}$ Para una visión sobre estas problemáticas ver José Luis RIVERO CEBALLOS (ed.), Crecimiento económico y política de empleo en las Islas Canarias, CC.OO, 2003. Antonio CÁCERES MORA, Análisis del desempleo en Canarias, Consejería de Trabajo, Sanidad y Seguridad Social, Santa Cruz de Tenerife, 1986.José Ángel RODRíGUEZ MARTíN, "La economía contemporánea (III). De la autarquía a la integración en la CEE" en Historia de Canarias, Vol. IV, Las Palmas de Gran Canaria, Prensa Ibérica, 1991. VV.AA., Canarias: La economía, Tenerife, Centro de la Cultura Popular Canaria/Cabildo de Tenerife, 1995.

${ }^{6}$ Ibídem. pág. 19.
} 


\section{La negociación para la entrada a la CEE en el bienio I983- 1985.}

La posición del gobierno autónomo para la negociación de la entrada de Canarias en el contexto de la adhesión española fue explicada a comienzos de diciembre de 1983. La mayoría parlamentaria apoyó la resolución propuesta. El documento fue defendido por el Consejero de Economía, Molina Petit. Se trataba de adecuar la integración a la CEE con el régimen económico y fiscal canario, renovado la década anterior, y reconocido en la Constitución española de 1978. "En los últimos años del franquismo se había logrado la aprobación de la Ley de 22 de julio de 1972 sobre el Régimen Económico y Fiscal de Canarias que reconocía y sancionaba una política económica y fiscal diferenciada del resto del Estado para las islas y permitía una financiación directa de las corporaciones locales: Cabildos y Municipios (...), se había recogido tras una larga negociación, en la Constitución de 1978 y en el Estatuto de Canarias. Había unanimidad en que el archipiélago canario debía constituir un capítulo aparte en las negociaciones de adhesión del reino de España a la Comunidad Europea, para mantener sus especificidades históricas en política económica y fiscal. Este era un punto de partida indiscutido y asumido por los negociadores españoles"7.

La intervención del Consejero de Economía fue una detallada exposición de motivos, seguida de tres propuestas, de las cuales debía escogerse una tras el oportuno debate y votación. El Consejero manifestó que la posición del gobierno era el fruto de un trabajo de estudio y de consulta, con distintos sectores y especialista sobre la mejor modalidad de integración de Canarias. Relató que, además de con los expertos de la Universidad, se mantuvo reuniones con los distintos agentes sociales y económicos de las islas. Las tres opciones que se ponían sobre la mesa encerraban consecuencias y riesgos diversos, que debían ser valorados antes de tomar una decisión en la sesión parlamentaria.

La opción uno implicaba la adhesión plena en los mismos términos que el resto del estado, pero con el mantenimiento de algunas salvedades de menor alcance "que

\footnotetext{
7 Teresa NOREÑA SALTO, "Canarias: De Comunidad Autónoma a región europea" Boletín Millares Carlo, №15. Las Palmas de Gran Canaria, Centro Asociado de la UNED. 1996, pp. 411-412.
} 
afectaban a la libertad comercial con terceros países, la no aplicación del IVA y medidas correctoras para que no subiera el índice de precios al consumo" ${ }^{\prime 8}$, para lo que sería necesario anular la tarifa exterior para la importación de algunos productos básicos alimentarios, así como para materias primas básicas para la industria insular, al objeto de que no se produzca el hundimiento de la pequeña y mediana industria, con el consecuente efecto de pérdida de puestos de trabajo y menor diversificación del sistema productivo. Paralelamente, la Comunidad Europea debía incluir a Canarias

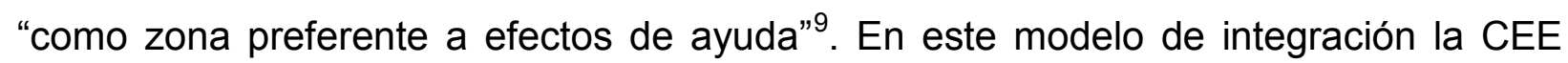
tenía que "hacer una reserva explícita del mercado del plátano, en el mercado peninsular", y que se mantuvieran las vigentes regulaciones de exportaciones de tomates y pepinos entre Canarias y Península. La pérdida de capacidad recaudadora de las administraciones locales por la merma del REF tendría que ser compensada con una financiación específica por parte del Estado para los Cabildos. No acabarían ahí las propuesta de compensación sino que, bien al contrario, el gobierno estimaba que debían ampliarse las demandas a otras áreas para las que habría de elaborar una lista concreta de peticiones. Entre éstas estaría la creación de zonas francas en puertos y aeropuertos y una zona libre bancaria ${ }^{10}$.

La opción dos, que a la postre sería la que aprobará el Parlamento, planteaba una integración en una situación especial ${ }^{11}$, que en síntesis sería la ampliación del modelo de relación que ya tenía con el Estado al conjunto de la CEE, y que no era una mera opción técnica o económica, sino que lo era también, y sobre todo, una apuesta política $^{12}$. La propuesta fue formulada de la siguiente manera: Canarias aceptaba todo el acervo legal comunitario, todas las normas, pero paralelamente su aplicación tendría una serie de excepciones, "primero, que no se apliquen los mecanismos de protección comunitaria frente a terceros, es decir, que podamos continuar con nuestro régimen de puertos francos como zona de libre comercio; segundo, no aplicación del Impuesto del Valor Añadido; tercero, no aplicación de la política agraria; y cuarto, por supuesto,

\footnotetext{
8 Ibídem pág.414.

${ }^{9}$ Diario de sesiones del Parlamento canario 1 de diciembre de 1983, n¹0, pág. 575.

${ }^{10}$ Ibídem. pág. 576.

11 Teresa NOREÑA SALTO, “Canarias...” op. cit. pág.414.

${ }^{12}$ Carmen Dolores WEHBE HERRERA, Canarias..., op. cit. pág. 58.
} 
creación de una zona de libre comercio para tanto productos agrícolas, como industriales, como industrializados en Canarias, entre Canarias y la Comunidad Económica ampliada"13. Esto significaba el mantenimiento del REF en los términos en que estaba reconocido entonces. Se recogía igualmente el hecho de que Canarias pudiera establecer en momentos puntuales tarifas especiales y derechos reguladores para defender las producciones isleñas agrícolas e industriales.

La tercera opción planteaba no estar en la CEE y firmar tipos de acuerdos preferenciales con la Comunidad, manteniendo un protocolo comercial específico con la Península para garantizar el mercado del plátano y otras exportaciones al conjunto del Estado, y un protocolo similar para las relaciones con Europa. "Canarias no se integra en la Comunidad Económica Europea, en cuyo caso no entra a formar parte de la comunidad y sería considerada a efectos comunitarios como si fuera o se tratase de un tercer Estado"14. En ese supuesto habrían dos hipótesis para el futuro de las relaciones de Canarias con el exterior, que consistirian en que Canarias no mantiene ningún tipo de acuerdo preferencial con la CEE, opción harto improbable, o bien, "mantiene relaciones con las Comunidades Europeas. Ejemplo, concluir acuerdos comerciales (caso de las islas Féroe)"15.

La posición del gobierno, y al parecer de la mayoría de las organizaciones económicas y sociales, se inclinaba por la opción dos, a tenor de la información emitida por el Consejero. "Las dos grandes patronales, CEOE y UNIPYME, que en Canarias están representadas por COREICA y CECAPYME, se han manifestado claramente (...) también en esa misma línea se han manifestado los dos grandes Sindicatos UGT y Comisiones Obreras y también FEDECO”16. De entre los grandes grupos empresariales quien no tenía una opinión cerrada en ese momento era la Cámara de Comercio de Tenerife, dado que manejaba un documento de 1981 que no había sido

\footnotetext{
${ }^{13}$ Diario de sesiones...lbídem, pág. 576.

14 Antonio PÉREZ VOITURIEZ y Oswaldo BRITO GONZÁLEZ, Canarias, encrucijada internacional, Tenerife, Ecotopía, 1982, pág. 87.

${ }^{15}$ María Asunción ASÍN CABRERA, Islas..., op. cit. pág. 257.

${ }^{16}$ Diario de sesiones...Ibídem pág. 577. UNIPYME (Unión de la pequeña y mediana empresa); COREICA (Confederación regional de empresarios de las Islas Canarias); CECAPYME (Confederación canaria de la pequeña y mediana empresa); FEDECO (Federación de desarrollo empresarial y comercial de Canarias).
} 
puesto al día. Los sindicatos nacionalistas, así como los partidos políticos nacionalistas de izquierda, apoyaban la opción tercera.

La mayoría de los expertos en derecho comunitario, fiscal e internacional o en economía, abogaban por la entrada con algunas excepciones ${ }^{17}$. De tal manera parecía evidente que la opción dos era la que concitaba un mayor consenso. Para algunos la integración debía serlo también en el plano de las políticas aduaneras, manteniendo una regulación especial para ciertos productos tal como opinaba el catedrático de organización económica internacional, Granell, o como señalaba el Instituto Alemán de Política de Desarrollo "Canarias (debe) tener un trato especial" ${ }^{18}$. Entre las principales preocupaciones de orden político que manifestaron los partidarios de la integración, con o sin excepciones, se encontraba la argumentación de que "la marginación de la CEE podía poner en peligro el reconocimiento del carácter europeo de Canarias desatando, por tanto, un problema de identidad social y cultural que no es admisible, y que podría tener consecuencias negativas para la paz social del archipiélago" ${ }^{19}$, según recogía el documento elaborado por Francisco Ucelay Sabina para la Conferencia de Regiones Insulares Europeas.

Se estimaba que los términos de la negociación incorporados en la opción dos eran perfectamente defendibles en Bruselas y que, además, iban a contar con el respaldo del gobierno del estado. El consejero Molina Petit, así lo transmitía al Parlamento: "También tengo que decirles que hemos encontrado el máximo de comprensión, tanto en Madrid, en los Ministerios de Asuntos Exteriores, como de Hacienda, y que ni teóricamente ni políticamente parece imposible conseguir la opción dos; y que la Comunidad, Bruselas, ha sido, hasta la fecha, comprensiva con las situaciones nuevas que han ido presentando los Estados miembros"20.

Los grupos parlamentarios fijaron su posición tras la intervención del gobierno. Entre los grupos nacionalistas primaba la opción tres como la que mejor se ajustaba a los intereses canarios. El diputado Gregorio Toledo, de Convergencia Nacionalista, adujo que los argumentos que usó Molina Petit para defender la opción dos quedaban

\footnotetext{
${ }^{17}$ Daniel CERDÁN, op. cit.

${ }^{18}$ María Asunción ASÍN CABRERA, Islas..., op. cit. pág. 259.

${ }^{19}$ Ibídem, pág. 261.

${ }^{20}$ Diario de sesiones...lbídem, pág.582.
} 
mejor encuadrados en la opción tres. Entendía este diputado que si Canarias aceptaba el acervo comunitario, tal y como se proponía hacer, se verían los intereses canarios envueltos en una maraña de leyes y normas europeas en las que el REF quedaría completamente desvirtuado o fuera de uso. "Porque una vez dentro, y la opción dos significa integrarse, si para nosotros ahora es enormemente dificultoso y sabemos que nuestro simple régimen económico y fiscal muchas veces nos cuesta que Madrid nos entienda, que se cometen agresiones continuas en forma de normas, disposiciones, continuamente; con Madrid que nos conoce desde hace más de quinientos años ¿qué va a suceder con la Comunidad Económica Europea con veintisiete años de legislación comunitaria que choca frontalmente con todas esas excepciones?"21. El diputado abogaba por quedarse fuera y establecer protocolos comerciales para cada uno de los sectores económicos afectados e interesados en hacerlo. "Esta es nuestra forma de vivir desde hace un montón de años; esto es lo más prudente"22, y si los acuerdos van resultando bien con el tiempo se podrá plantear una integración paulatina, pero si la cosa no va bien, no se verá Canarias atada en una red de tratados y normas comunitarias de las que luego no podrá zafarse.

La organización insular de Fuerteventura, Asamblea Majorera, se posicionó igualmente en contra de la opción dos y se inclinó por la tercera, arguyendo además de la defensa del modelo conseguido con el REF, que su defensa y su mantenimiento en las condiciones del momento son "los restos de soberanía verdadera que le queda al pueblo canario para protagonizar su propia historia"23. Los majoreros entendieron, igual que Toledo, que en el fondo los argumentos que usó el Consejero para defender la opción dos, en realidad tenían mejor fundamento para defender la opción tercera. Por último, AM estimaba que la entrada en la CEE conllevaba la aceptación implícita de pertenecer también a la OTAN. Decía: "No aceptemos el propósito comunitario de unificar su política exterior (asimilando) a medio plazo Mercado Común con pertenencia a la OTAN". Esta lectura que los majoreros veían con nitidez era absolutamente contraria a la posición de su organización, porque, "Asamblea Majorera tiene un breve ideario, tan breve ideario que jocosamente lo llamaría breviario y en uno

\footnotetext{
${ }^{21}$ Ibídem. pág. 584.

${ }^{22}$ Ibídem.

${ }^{23}$ Ibídem. pág. 586
} 
de los lugares de honor de ese breviario está nuestra oposición a la pertenencia o a la permanencia en la OTAN"24. La posición de este grupo era similar a la de Convergencia Nacionalista, en cuanto a que lo que se debía hacer era negociar con Madrid y Bruselas los protocolos de relaciones comerciales y de colaboración técnica que fuesen más favorables para Canarias.

De entre los grupos opositores el mayor de todos y que mantuvo una argumentación más extensa fue el integrado en el grupo parlamentario Izquierda Canaria, conformado a su vez por la Unión del Pueblo Canario-Asamblea Canaria (UPC-AC) y por el Partido Comunista de España. En este grupo la posición adversa al protocolo 2 la sostuvo UPC-AC, mientras que el PCE se mostró a favor del protocolo 2, o en cualquier caso, a favor de la integración pero manteniéndose fuera de la política aduanera y defendiendo el REF, en términos bastante parecidos a los defendidos por el gobierno canario. No veía mal el PCC-PCE que se celebrase un referéndum consultivo que ayudase a fortalecer la posición del gobierno canario en la negociación con Madrid.

La propuesta de la UPC-AC la defendió el diputado Oswaldo Brito, profesor de Historia en la Universidad de La Laguna y destacado dirigente político y sindical de la izquierda nacionalista. El portavoz de la UPC-AC, como ya habían hecho anteriormente parlamentarios de otros grupos, criticó al gobierno que no hubiese suministrado el informe con tiempo suficiente para su estudio. Estimaba que lo aportado al Parlamento no era un informe en el verdadero sentido de la palabra, sino una serie de argumentaciones y datos ya elaborados para exponerlos y conseguir la suma de los grupos parlamentarios, sin haber tenido acceso ni tiempo para elaborar una contrapropuesta mejor fundamentada, tal y como este importante tema requería. Los informes independientes de técnicos y especialistas, y otros elaborados por los servicios jurídicos del gobierno, no han sido puestos a disposición de los parlamentarios. El diputado de la izquierda nacionalista infería que el informe del consejero de economía usa datos incompletos, unos anticuados, otros sin ponderación

\footnotetext{
${ }^{24}$ Ibídem. pág. 587.
} 
ni actualización, y que por todo ello el documento es un mal resumen sin fundamentación ${ }^{25}$.

Paralelamente, criticaba que el informe presentado no elaboraba un plan de futuro a medio y largo plazo, sino que daba por buena la situación del momento, como si no se estuviese en un contexto de crisis económica con altas tasas de paro, subdesarrollo de la economía y la sociedad canaria. De entre las muchas dudas que expresaba este grupo, estaba la sospecha de que el acuerdo que se trataba de sacar en el Parlamento de Canarias no tuviese el firme respaldo del gobierno del estado, sino solo en parte, pudiendo verse desustanciado lo acordado en Canarias en las negociaciones entre Madrid y Bruselas. "Segunda cuestión: si evidentemente el tema está ya concretado con Madrid, iseñores!, dígase aquí, en qué condiciones; y si Madrid está dispuesta a asumir todos y cada uno de los puntos de esa alternativa, como un elemento de política de estado, dispuesta, por tanto, incluso, a frenar la negociación con la Comunidad si ese tema no se logra y si no, dígase que estamos intentando una formulación que veremos lo que pasa" ${ }^{26}$. Por todo ello, el grupo UPC-AC estimaba como mejor opción no entrar en la CEE y mantener relaciones especiales, y tras un periodo previo, con un referéndum consultivo de por medio, decidir la mejor fórmula de relación. Se señalaba a tal efecto el caso de las islas Féroe como modelo de imitación. En el caso de que finalmente la integración se llevase a efecto, la propuesta de este grupo demandaba un estatuto especial "que integraría un acuerdo especial CanariasEstado, garantizador del régimen económico-fiscal mejorado, adaptado al establecimiento de un plan económico y social preferente, que afronte la eliminación de la actual dependencia y de los desequilibrios. Conferir a Canarias status especial de territorio archipielágico con un ajuste al marco estatutario, a tales exigencias precedentes: Azores, Madeira, Féroe, etcétera-, declaración del territorio del Archipiélago como zona neutral; fijación de un protocolo especial en la adhesión estatal a las Comunidades que determine como política de estado la protección especial a las producciones agrícolas e industriales canarias; un acuerdo preferencial con la Comunidad Económica Europea a los efectos de eliminar o atenuar los impactos negativos de la TEC (Tarifa Exterior Común) y de las políticas sectoriales de la

\footnotetext{
${ }^{25}$ Ibídem. pág. 588.

${ }^{26}$ Ibídem. pág. 590.
} 
Comunidad y reconocimiento de Canarias como territorio fuertemente deprimido y dependiente" ${ }^{27}$. Para cualquiera de las eventualidades, integración y sus modalidades como la no integración, este grupo defendía generalizar el debate socialmente, y tras ello llevarlo a un referéndum ciudadano.

Existían problemas que preocupaban a algunos sectores de la ciudadanía en las islas, uno de ellos era que la entrada en la CEE implicase igualmente la entrada en la OTAN, y esta opción militarista era ampliamente rechazada por la mayoría social, como posteriormente quedó de manifiesto en el referéndum de marzo de 1986, y también "los posibles efectos negativos para los trabajadores canarios, que se derivarían de la libre circulación de mano de obra si Canarias se integraba en la CEE. Este aspecto era, y sigue siendo, creíble por la baja calificación de los trabajadores canarios y la inmigración de los peninsulares y extranjeros cualificados, para ocupar mejores puestos de trabajo en todos los sectores laborales: la competencia en el mercado de trabajo era una realidad y se utilizó constantemente por los partidos y sindicatos que se oponían a la integración de Canarias a la CEE"28.

Por el Centro Democrático y Social (CDS), tomó la palabra Fernando Fernández, y comenzó, como los grupos que le antecedieron, criticando la marginación sufrida por el Parlamento en el debate de este tema, por la falta de información recibida con anterioridad al informe que ahora ocupaba las intervenciones de los parlamentarios.

Cuando entró en materia lo hizo señalando el hecho de que las pretensiones del gobierno canario (opción 2) podían entrar en contradicción con los principios de la propia CEE, porque plantear quedar fuera de la unión aduanera era no querer entrar en el núcleo fundamental de la Comunidad, que justamente se apoyaba sobre el desmantelamiento de las aduanas en el interior de la $\mathrm{CEE}^{29}$. $\mathrm{Y}$ los ejemplos que se usaron para explicar que existían salvedades con pequeños territorios a los que la CEE había dejado fuera de su unión aduanera, no convencieron al diputado centrista, por no quererse ver comparado con algunos de esos territorios, particularmente con Gibraltar,

\footnotetext{
${ }^{27}$ Ibídem. pág. 591.

${ }^{28}$ Teresa NOREÑA SALTO, “ Canarias...”, op. cit. pág. 418.

${ }^{29}$ Algunos diputados querían ponerse la tirita antes de la herida, a buen seguro con la intención clara de hacer oposición de desgaste al gobierno socialista.
} 
Ceuta y Melilla. El primero, porque consideraba que era una colonia inglesa y "nosotros no somos una colonia" ${ }^{30}$. En relación a la comparación con Ceuta y Melilla, la consideraba más grave que la anterior, porque en su opinión esa comparación podía poner a Canarias en una situación peligrosa. "Hay una cuestión de orden político que nos preocupa. El hecho que desde Canarias o desde España en la totalidad se acepte una similitud de tratamiento para Canarias en relación a Ceuta y Melilla porque ¿quién nos dice que nuestro vecino de las costas africanas, pasado algún tiempo o en algún momento, cuando lo estime oportuno, no pueda esgrimir este argumento diciendo que Canarias tiene el mismo tratamiento que Ceuta y Melilla puesto que, asimismo, nosotros lo hemos reconocido? Pensemos lo que en el futuro pueda comportar esta posición"31. El ancestral y, diríamos también, cerval temor a Marruecos forma parte de cierta tradición discursiva en las islas, que entiende que las ansias expansionistas marroquíes pueden no detenerse ante el Archipiélago canario. No es ajeno a ello y desde luego ayuda a darle peso a esta teoría la cercana experiencia en el Sáhara Occidental, en donde se puso de manifiesto el apetito expansionista del nacionalismo marroquí. Ese discurso ha servido también como coartada antinacionalista canaria a las élites españolistas.

Sin querernos parecer a esos territorios, prosigue el parlamentario centrista, su voluntad es ser europeo de primera, manteniendo "nuestras peculiaridades". Pero para Fernández la cuestión no es sólo si Europa no se va a mostrar comprensiva, "el problema está, en si Madrid va a entender estas razones y el vigor con que desde el Gobierno Central se defiendan las peculiaridades canarias"32. Lo que se le pide a Madrid es que trate de salvaguardar los intereses de las burguesías importadoras y de las elites agroexportadoras. EI CDS pensaba que con la fórmula 2 el sector que podría ser afectado de manera negativa era el agroexportador, y manifestó su preocupación a este respecto. En los años siguientes se vería cómo los grupos de presión de los exportadores lograron modificar el protocolo de adhesión de Canarias hacia el modelo 1 con correcciones.

\footnotetext{
${ }^{30}$ Diario de sesiones..., Ibídem. pág. 600.

31 Ibídem.

${ }^{32}$ Ibídem. pág. 601.
} 
Francisco Marcos, del grupo popular, se centró primeramente en desechar la opción 3 (no entrada en la CEE). Estimaba que ante la situación de crisis económica que atravesaba el país, era mucho más deseable abordarla desde dentro del Mercado Común que desde fuera. Por supuesto, también entendía que los intereses canarios y su defensa se haría con más fuerza desde dentro que quedándose fuera, cuando el resto del país iba a estar dentro. No obstante, esta posición no dejaba de lado el hecho de que había que mantener el REF. Es decir, en síntesis, se repetían los argumentos expuestos por los demás grupos favorables a la entrada. El razonamiento que expuso el grupo popular, incluía la obligatoriedad para el Estado de defender esa postura, dado que en el articulado del REF se mandataba al gobierno a su defensa, en caso de que el Estado se incorporara a organizaciones supranacionales. La síntesis de la posición de la derecha quedaba así: "(que) el Gobierno Español cumpla con dicha obligación y exija en las negociaciones sobre el ingreso de España en el Mercado Común el respeto a las peculiaridades del régimen especial de Canarias. En tal sentido, manifestamos que el Gobierno Español a la hora de negociar la adhesión a la Comunidad debe exigir y defender para la región canaria un estatuto especial donde el esquema de las relaciones en lo económico y comercial, que ligan actualmente a Canarias con el resto de España, deberá ser trasladado a las relaciones que vincularán a Canarias con toda la Comunidad Económica"33. Con ello, el grupo popular solicitaba que la entrada de Canarias tuviese un periodo de adaptación de diez años, al objeto de una mejor adecuación de la estructura productiva a las exigencia de la CEE. En ese periodo de diez años la Comunidad "sostendrá para Canarias la consideración de tercer país a efectos de mantener las restituciones hasta la dotación total de la economía canaria" ${ }^{34}$. Esto es lo que el gobierno del Estado tendría que negociar en opinión de este grupo político.

Con todas las posiciones expuestas la sesión se retomó tras el intervalo negociador, y se propusieron dos resoluciones para ser votadas. La primera fue la planteada por el grupo Izquierda Canaria, y la segunda por CDS, populares y socialistas, los cuales habían encontrado un punto de acuerdo intermedio. La resolución de la Izquierda Canaria fue resumida en seis puntos. Comenzaba señalando

\footnotetext{
${ }^{33}$ Ibídem. pág. 603.

${ }^{34}$ Ibídem. pág. 607.
} 
que debía ser el propio Parlamento el órgano que reflejase la posición del gobierno autónomo. Como pensaron que los intereses canarios no estaban claramente defendidos en la comisión negociadora del Estado con Bruselas, propusieron crear una comisión de seguimiento de las negociaciones, en la que estuvieran presente todos los grupos del Parlamento. Esta comisión sería avalada por el gobierno central. Mantuvieron la petición de sancionar la decisión por vía referéndum. Reclamaban una mayor capacidad competencial en asuntos económicos y sociales, y defendían que, independientemente de la modalidad de adhesión, se debía garantizar el estatuto de neutralidad y la condición de plataforma de paz del Archipiélago. En el último punto, introdujeron la propuesta de mantenerse fuera de la unión aduanera y del IVA. Esta resolución obtuvo el apoyo afirmativo de siete diputados, el negativo de cuarenta y ocho y una abstención. Quedó, por tanto, derrotada.

Fue la resolución presentada por los otros tres grupos la que obtuvo el respaldo mayoritario de la Cámara, con cincuenta votos afirmativos, seis negativos y ninguna abstención. Cuatro diputados se encontraban ausentes. Esta propuesta consistía en la integración de Canarias en la CEE y, a la vez, la defensa de las peculiaridades económico fiscales isleñas. En síntesis, la opción dos con algunas pequeñas modificaciones consensuadas entre los tres grupos. La propuesta de resolución aprobada comprometía a que el gobierno de Canarias elevase al del Estado la resolución ganadora en la Cámara, mantuviese informada a la cámara autonómica de la marcha de la negociación y, finalmente, trajese de nuevo al Parlamento el acuerdo final con las disposiciones referidas a Canarias, firmado entre el Estado y Bruselas. En estos puntos no había propuesta de fondo de ningún tipo, sino ajustes en las formas y los procedimientos para dar y recibir información. Salió ganador, con el respaldo de CDS y de AP, el modelo socialista de entrada en la CEE (opción 2), planteada al inicio de la sesión.

Lo que había aprobado el Parlamento en la sesión del 1 de diciembre de 1983 era: A) "Integración de Canarias en la CEE, es decir, Canarias pasa a ser considerada territorio comunitario. B) Aceptación de los principios, las normativas y políticas comunitarias generales, tanto de derecho derivado, como dimanantes de políticas sectoriales, pesquera, industrial, monetaria, financiera, social, de libertades de movimientos de capitales, institucional, de transportes, etc., con las siguientes 
excepciones: -No aplicación del IVA . No aplicación de la política agraria. Creación de una zona de libre comercio en ambos sentidos, entre Canarias y la CEE ampliada" ${ }^{35}$. Además, se proponía el mantenimiento de la cuota de mercado para la industria tabaquera, y para el sector agroexportador de tomates, pepinos y el mantenimiento del mercado peninsular para el plátano. También se pedía un periodo de diez años en cuanto a la libre circulación de personas, para contener la llegada masiva de trabajadores europeos a las islas.

Este documento fue presentado en Bruselas por el gobierno del Estado en febrero de 1984. Europa aceptó básicamente las propuestas españolas sobre Canarias, pero algunos sectores productivos quedaron descontentos con el documento enviado por Bruselas. En particular, los exportadores de tomates, pepinos, berenjenas y calabacines que tendrían que afrontar precios de referencias establecidos por la CEE, al haber quedado Canarias fuera de la política agraria común. La preocupación de las autoridades europeas al aceptar lo esencial del documento canario hacía "hincapié en que la entrada en la Comunidad no debería originar una recesión económica en Canarias que amenazara su estabilidad política" ${ }^{36}$. Aún resonaba en Madrid y en Bruselas el pujante nacionalismo autodeterminista de la década anterior, de ahí que hubiese cierta atención especial a los problemas sociales y económicos.

Además de a los sectores señalados, el malestar se extendió al pesquero, que veía peligrar su futuro. El 22 de junio de 1985 hubo un pleno en el Parlamento que rechazó los términos del documento presentado por Bruselas, por 30 votos (toda la oposición), contra 27 favorables (grupo socialista).

\section{El protocolo $n^{\circ} 2$ y la dimisión de Saavedra}

Tras conocerse el documento que envió Bruselas, los sectores afectados se movilizaron para que el gobierno canario no lo aceptase. El mes de mayo estuvo agitado con las convocatorias de manifestaciones de los agricultores. Finalmente el 16 salieron miles de ellos en las dos islas centrales. Varias decenas de miles desfilaron

\footnotetext{
${ }^{35}$ María Asunción ASÍN CABRERA, Islas..., op. cit. pp. 263-264.

${ }^{36}$ Francesc GRANELL, "Canarias y el ingreso en la Comunidad Europea”, El País, 31/5/1985. (visitado $30 / 11 / 2016)$.
} 
por las calles de Las Palmas de Gran Canaria y de Santa Cruz de Tenerife, con el argumento de que las pérdidas para el sector se elevarían a los 40.000 millones de pesetas, y que afectaría negativamente a 75.000 puestos de trabajo. Indudablemente parecía que las cifras estaban infladas, pero era cierto que los agroexportadores tenían la impresión de que se verían abocados a una nueva reconversión en el sector. Práctica que, por otra parte, había sido histórica en la agricultura canaria desde el siglo $\mathrm{XVI}$. El campo canario tendría que competir en condiciones desfavorables con las hortalizas del levante español, de los Países Bajos o de Marruecos.

La Comisión Regional de Agricultores Canarios (CRAC) había sacado los datos estadísticos de evaluación de las pérdidas futuras sumando el monto total de las exportaciones agrícolas del año 1984, sin contar el plátano. Los datos manejados hablaban de las toneladas producidas en los distintos productos (papas, judías verdes, cebolla, tomate, pepinos, pimientos, berenjena, flores, plantas y aguacate) que ascendían a 277.113 toneladas de productos, en los que el tomate era el fruto hegemónico, ocupando la cantidad de 185.746 toneladas. Además, de los problemas en el mercado europeo a partir del 1 de enero de 1990, la Península a estos efectos sería también territorio europeo, con lo que los productos canarios exportados al resto de España serían gravados con precios de referencia. Los agricultores sostenían que las consecuencias se notarían también en las industrias relacionadas, y en la pérdida de actividad en el sector de los puertos, al verse mermada su actividad comercial.

Los agricultores decían: "Gobierno atiende, Canarias no se vende", "El campo unido jamás será vencido", "Los agricultores no queremos emigrar", y otras consignas que manifestaban el malestar del sector. En la carta que entregaron al presidente del Parlamento, el socialista Pedro Guerra, la CRAC, reseñaba que "Las Islas Canarias fueron la pioneras de las exportaciones hortofrutícolas a Europa, que han continuado ininterrumpidamente hasta la fecha. Las condiciones en que quedará la agricultura canaria en la CEE, no beneficiará a ningún sector de la misma, y está muy lejos del documento aprobado en su día por el Parlamento canario, ya que en el tratado se condiciona la libre entrada de los productos hortofrutícolas de este Archipiélago" ${ }^{37}$. También se le decía al gobierno canario que no estaba en el ánimo de los convocantes

\footnotetext{
${ }^{37}$ Diario de Avisos, 17/5/1985.
} 
de la manifestación hacer oposición política al gobierno, sino lograr de éste el compromiso "de conseguir para la agricultura canaria el mismo tratamiento que va a tener la del resto de España"38. Junto con la agricultura, los sectores industriales del tabaco y la pesca también sintieron que sus intereses no quedaban bien representados en ese documento, dado que el asunto de la contingentación sí podía afectar a esas dos actividades productivas. El acuerdo final firmado entre el gobierno español y el Comité de Representantes Permanentes de los Gobiernos de los Estados miembros (COREPER), estableció "la fijación y determinación de los contingentes aplicables a la exportación de productos agrícolas, pesqueros y el tabaco (...) la definición de lo que se habrá de considerar como flota canaria y flota peninsular-comunitaria" ${ }^{39}$.

El gobierno tenía otro punto de vista, como quedó de manifiesto en el debate parlamentario del día 22 de junio de 1985, en el que nuevamente se abría una amplia discusión sobre el tema de la integración canaria en la CEE. Incluso, con antelación a dicho debate, expresó el Consejero de Agricultura y Pesca, Felipe Pérez Moreno, la impresión de que "algunos líderes agrarios manipulan para sus oscuros intereses la integración canaria en la CEE" ${ }^{40}$. El Consejero refutaba los puntos principales que llevaron a las movilizaciones señalando que no era verdad el riesgo de pérdida de 70.000 puesto de trabajo, ni las trabas para los productos agrícolas canarios de exportación. Según el gobierno los precios de referencia no se aplicaban al conjunto de los productos agrícolas de exportación sino sólo a tres (tomate, pepino y berenjena). En relación a la contingentación explicó que ella se aplicaría teniendo como referencia el volumen de producción de los años anteriores, y como lo previsible era que no hubiese un aumento de lo producido, lo productos canarios entrarían al mercado comunitario sin trabas, aunque Canarias no estuviese en la Política Agraria Común (PAC). Por otra parte, la reserva del mercado peninsular para el plátano se había conseguido para los años siguientes, con lo cual el principal sector agroexportador podía respirar tranquilo en el futuro inmediato, al menos hasta 1995.

El debate, ciertamente engorroso para el conjunto de la sociedad, por lo técnico y especializado del mismo, mantuvo ocupado a políticos, empresarios e intelectuales,

\footnotetext{
${ }^{38}$ Ibídem.

${ }^{39}$ María Asunción ASÍN CABRERA, Islas..., op. cit. pág. 272.

${ }^{40}$ Diario de Avisos, 19/5/1985.
} 
quienes participaban en los periódicos insulares con sus respectivas razones y puntos de vistas. No así la mayoría social, que no se sintió interesada ni concernida. Fueron los distintos grupos económicos sectoriales los que monopolizaron el discurso sobre la adhesión a la $\mathrm{CEE}^{41}$.

Cuando se inició el segundo gran debate en el Parlamento de Canarias sobre el asunto, España ya había firmado el acta de adhesión a la CEE, el día 12 de junio de 1985, para que entrase en vigor el 1 de enero de 1986. Canarias había quedado enmarcada en lo que se conoció como el Protocolo n ${ }^{\circ} 2$ del Acta de Adhesión.

Este protocolo se hacía extensivo a la plazas coloniales de Ceuta y Melilla. Lo fundamental de él era que no contemplaba esos territorios dentro del marco aduanero de la CEE, y se reservaba la posibilidad de que para algunos productos se aplicara a los intercambios comerciales con estos tres territorios "el régimen que aplica a sus intercambios exteriores" ${ }^{42}$. En líneas generales, el protocolo recoge la lista de excepcionalidades demandadas por los distintos sectores productivos de la comunidad autónoma.

La sesión parlamentaria se inició con la moción presentada por el grupo popular. Iba encaminada a que el ejecutivo determinase qué aspectos del documento aprobado en 1983 no fueron recogidos en el acta de adhesión, y qué medidas adoptaría para proteger a los sectores que quedaban perjudicados por la firma del tratado. Asimismo, conminaba al gobierno a que dijese qué medidas pensaba tomar para que la tasas fiscales no perjudicasen la producción canaria, en el entendido de que en "Canarias se aplicará la política fiscal comunitaria" ${ }^{43}$. Parece obvio señalar que el grupo popular no había comprendido los términos del acuerdo con la CEE, porque tal y como contestó el grupo socialista "el protocolo canario establece específicamente la no aplicación del IVA (...) y la no aplicación de las accisas ${ }^{44}$ del tabaco y los alcoholes. Y respecto de nuevas accisas que pudieran producirse (...) España en representación de Canarias, tendría que actuar, al igual que actúa Francia en representación de los DOM (...)

\footnotetext{
${ }^{41}$ Carmen Dolores WEHBE HERRERA, Canarias..., op. cit. pág. 86.

${ }^{42}$ Acta de Adhesión del Reino de España a las Comunidades Europeas. Protocolo $n^{\circ} 2$. Art.1, punto 5.

${ }^{43}$ Diario de sesiones de 22 de junio de 1985, nº 40, pág. 2621.

${ }^{44}$ Impuesto especial indirecto que grava el consumo de determinados artículos como el tabaco, alcohol, etc.
} 
añadiendo un protocolo a cada una de esas accisas (...) indicando que tal accisa no sería de aplicación al DOM"45.

Uno de los argumentos críticos más usados por los grupos de la oposición era que el gobierno de Madrid y el de Canarias, los dos del PSOE, habían incumplido el precepto constitucional, relativo a que el gobierno del Estado debía consultar al Parlamento canario para acuerdos que implicasen una reforma del Régimen Económico y Fiscal (REF), tal como recoge el artículo 45.3 del estatuto de autonomía y la disposición adicional tercera de la Constitución de 1978, que establecía que el REF, para ser modificado, "requerirá informe previo de la Comunidad autónoma".

El gobierno acusó a los grupos de la oposición de que con su actitud podían alentar el independentismo, y el presidente desde el comienzo de la sesión amagó con que si no se aprobaba el documento dimitiría. Esto fue motivo de malestar en los grupos que entendieron dicho gesto como un chantaje para orientar el sentido del voto. La oposición de derecha e izquierda logró concretar una enmienda conjunta, que recogía una serie de propuestas técnicas de orden fiscal, la renegociación de los cupos agrarios, y reprochó al gobierno que no hubiese cumplido los compromisos aprobados en el Parlamento en 1983, y no se hubiese traído a la Cámara el documento de adhesión con anterioridad a que el gobierno lo hubiese firmado, requisito que consideraban básico para poder dar su voto afirmativo.

La moción de la oposición fue aprobada con 30 votos a favor y 27 en contra. El informe subsiguiente que aprobó esta mayoría de parlamentarios opositores lo hizo en Ios siguientes términos: "El Pleno del Parlamento de Canarias formula su rechazo al tratamiento dado a la Comunidad Autónoma de Canarias en el trámite de cumplimiento de lo previsto en la disposición adicional tercera de la Constitución y articulo 45 del Estatuto de Autonomía de Canarias. En este sentido expresamos nuestra convicción de que estamos ante un informe de carácter vinculante sobre la base de la normativa expresada anteriormente. Por todo ello: Primero. Se informa negativamente el proyecto de ley orgánica presentado al Congreso de los Diputados para la ratificación del

\footnotetext{
${ }^{45}$ Diario de sesiones, Ibídem. p. 2624. DOM son los Departamentos franceses de ultramar Guadalupe, Martinica, Guayana francesa, Reunión y Mayotte. Ver, Ana CRESPO SOLANA y Ma Dolores GONZÁLEZ RIPOLL, Historia de las antillas no hispanas, Madrid, CSIC, 2011. Alain-Philippe BLÉRALD, La question nationale en Guadeloupe et en Martinique; essai sur l'histoire politique, Paris, L'Harmattan, 1988.
} 
Tratado de Adhesión a la Comunidad Económica Europea por las siguientes causas: a) Por presentar profundas diferencias con el acuerdo del Parlamento de Canarias de 1 de diciembre de 1983. b) Por afectar gravemente a sectores agrícolas, industriales y pesqueros del archipiélago. c) Por establecer restricciones en las relaciones comerciales con la Comunidad Económica Europea ampliada, no limitándose el libre acceso de los productos comunitarios al mercado canario. d) Por no obtenerse garantías para posibilitar un desarrollo económico y social del archipiélago en el futuro. e) Por limitarse gravemente el marco competencial de la Comunidad Autónoma Canaria en todo lo referente a su Régimen Económico y Fiscal. Tal circunstancia representa en la practica la desaparición del REF, en la forma conocida actualmente, y su sustitución por unas pautas con acusado carácter de discrecionalidad abierta que emanarán en el futuro de los centros decisorios de la Comunidad Económica Europea, mediante los mecanismos de cesión de soberanía que el tratado, como compromiso internacional, comporta. $2^{\circ}$. El Parlamento considera que el marco futuro de relaciones de Canarias con la Comunidad Económica Europea ampliada, y la adaptación del REF a esta circunstancia, es inseparable de una efectiva asunción de competencias en este ámbito por la Comunidad Autónoma de Canarias" ${ }^{\mathrm{N}}$.

Tras la votación de dicha resolución Saavedra presentó su dimisión, no sin antes defender el quehacer del gobierno en el proceso de negociación. El presidente acusaba a la oposición de manipular la información y de ser responsable de que no hubiese habido más debates, porque era la oposición quien tenía la mayoría en el Parlamento, para haber propuesto e impulsado los debates que considerase necesario llevar a cabo. La defensa del documento que negoció el gobierno del Estado en Bruselas recogía las demandas que habían sido aprobadas por el Parlamento canario en 1983 y quedaba garantizado el REF. Anotó que quedaba abierta en el futuro la revisión de la modalidad de entrada, y la solicitud de la plena integración y la negociación de nuevas excepciones. El tema canario ha sido el más debatido y el único que ha mantenido una excepcionalidad entre el conjunto de las autonomías de España, y el debate sobre la identidad de los canarios ha estado presente en todo el proceso desde que arrancó esa preocupación tras la muerte del dictador. Para Saavedra, la negociación con la CEE ha fortalecido la identidad canaria y se enmarca

\footnotetext{
${ }^{46}$ Diario de sesiones, Ibídem. pág. 2634.
} 
en la tradición histórica de sostenimiento y reconocimiento de los problemas específicos y sus respuestas también específicas. La construcción de la nueva identidad canaria fortalecida en el marco de la autonomía se ha forjado en la negociación constante con el gobierno central, como una necesidad impostergable "porque nuestros problemas derivados de nuestro hecho geográfico, de nuestro alejamiento del resto del territorio de la nación, de nuestras condiciones climatológicas exigían una respuesta específica, un tratamiento específico por parte de los legisladores nacionales" ${ }^{47}$. El reconocimiento a las singularidades canarias será aceptado no sólo por el gobierno del Estado, sino que se ampliará al conjunto de los miembros de la CEE. Desde el comienzo de los planteamientos autonomistas a principio de los setenta, este objetivo formaba parte del presupuesto estratégico una vez que España formara parte de la CEE. La identidad canaria pasaba por adaptar su tradición librecambista y su adaptación a la nueva realidad. Este hecho diferenciado "es una característica económica, es una característica comercial, es una característica fiscal, pero, en definitiva, es lo que nos diferencia básicamente de los españoles a la hora de buscar posibles signos de identidad al margen de otros añadidos de tipo cultural que puedan derivarse de nuestra relaciones con América y de nuestras relaciones con África, que, igualmente, han contribuido a formar parte de ese acervo y de nuestra propia identidad personal" 48 .

El presidente luego pasó a criticar la posición de los partidarios de la no entrada en la CEE, y adujo que en las relaciones de los países acogidos a la convención de Lomé, los países África, Caribe, Pacífico (ACP), que eran puestos como ejemplo a seguir, sus productos, como el tomate por ejemplo, tenían peores condiciones de acceso al mercado comunitario que las recogidas en el acuerdo preferencial de España con la $\mathrm{CEE}^{49}$ de 1970 y que, por tanto, no sería esa posición la que querrían para sí los agricultores que se habían manifestado en el mes de mayo. Por eso el presidente sostiene que los partidarios de la opción tres no representan los intereses

\footnotetext{
${ }^{47}$ Ibídem. pág. 2637.

${ }^{48}$ Ibídem. pág. 2638.

${ }^{49}$ Sobre este particular consultar Raimundo BASSOLS, España..., op. cit. Ramón TAMAMES, La Unión..., op. cit. En especial ver la parte VI. Un detallado estudio sobre todos los aspectos del complicado proceso de negociación desde principios de los 60 hasta 1986. Ramón TAMAMES, Guía del MCE..., op. cit. Pedro MONTES, La integración..., op. cit. Francesc MORATA y Gemma MATEO (eds.), España en Europa..., op. cit. Berta ÁLVAREZ-MIRANDA, El sur de Europa..., op. cit.
} 
de los agroexportadores, sino la de los partidarios del derecho a la autodeterminación de "vocación africanista" ${ }^{50}$. Para Saavedra estos parlamentarios representan a los que se presentaron a las elecciones "pensando que somos una colonia, que somos una economía dependiente -que es el término que se aplica para no hablar en algunos casos de que somos una colonia- y que como tal no tenemos que ir a ninguna fórmula de integración a la Comunidad"51. Una exageración a toda luces que se permitía el presidente de cara a debilitar la posición de los partidarios del no, en donde no había nadie que pensase exactamente las cosas como estaban siendo esbozadas, y porque entre los partidarios del no las visiones y los puntos de vista sobre Canarias eran diversos. El presidente planteó una moción de confianza sobre su mantenimiento al frente del ejecutivo, y si tras ella perdía la confianza, presentaría su dimisión.

Las intervenciones de los siguientes grupos repitieron los argumentos ya expuestos, aunque la que llevó a cabo el representante de Izquierda Canaria, pero del sector del PCE, prefiguró la opción de lo que posteriormente se conocería como el pacto de progreso, realizado entre la izquierda parlamentaria y el PSOE hasta el final de la legislatura en 1987. Entre los puntos que planteó el diputado comunista Sanjuán, tal pacto debería de llevar adelante la reforma administrativa de la comunidad autónoma, conocida como ley de cabildos y una ley de aguas, entre otras medidas de alcance e interés social. La propuesta atrajo la atención del PSOE, que la vio como una salida a la situación de minoría en que se encontraba tras el debate sobre la CEE. No obstante, aún debería aclararse la posición de los grupos de izquierda sobre el documento de entrada en la CEE.

Los grupos mayoritarios de la derecha, CDS y AP, fueron muy beligerantes con el acuerdo alcanzado, y aunque sin razones de peso, mantuvieron una distancia ficticia en relación a la posición del gobierno, que es lo que llevó al portavoz socialista a preguntarse: “¿Qué razones profundas pueden haber incidido en esta coincidencia -por

\footnotetext{
${ }^{50}$ Diario de sesiones..., $\mathrm{n}^{\circ}$ 40, pág. 2638.

51 Ibídem. El presidente Saavedra hacía aquí una simplificación excesiva sobre el concepto de dependencia, reduciendo su significación de manera injustificada. Para una visión sobre qué uso del concepto de dependencia se hacía entonces, habría que remitirse a las obras clásicas de autores como Samir Amín, Gunder Frank, Celso Furtado y otros. Para un balance sobre dicha teoría se puede consultar Francisco LÓPEZ SEGRERA (ed.), Los retos de la globalización, Ensayo en homenaje a Theotonio Dos Santos, Caracas, Unesco, 1998. En particular, el artículo del homenajeado que lleva por título: "La teoría de la dependencia un balance histórico y teórico".
} 
lo menos tendrán que reconocerme que extraña- entre AP (...) y el nacionalismo de izquierda radical en esta Cámara?" ${ }^{22}$. La contestación a esa pregunta retórica fue: una estrategia de acoso al gobierno socialista y, la segunda más alambicada, era entender que la posición de AP de aliarse con la opción del no al protocolo 2 era para favorecer una adhesión completa y sin matices que incluyera incluso la pérdida definitiva del REF. La idea era que la pendulación de AP a la izquierda era para forzar una salida completamente a la derecha, entendiendo ésta como la incorporación a la CEE sin matices, en iguales condiciones que el resto del Estado. La votación la perdió el gobierno por 27 votos frente a 30 , tras lo cual el presidente presentó su dimisión.

\section{El pacto de progreso y la adhesión a la CEE}

La recomposición del gobierno se hizo por la izquierda. El conocido como pacto de progreso salvó el resto de la legislatura y permitió a los socialistas seguir en el gobierno hasta 1987. Las izquierdas habían llegado a un acuerdo sobre la CEE, que pasaba por la aceptación de los términos del documento de adhesión presentado por el gobierno de Madrid en Bruselas. Canarias entraba con la modalidad del protocolo 2, lo cual permitía salvaguardar la vigencia del REF, modificándolo y adaptándolo a las nuevas condiciones derivadas de la entrada en la CEE.

El nuevo gobierno fue muy criticado, incluso por sus antiguos socios de la primera parte de la legislatura, que lo acusaron de no haber cumplido las promesas hechas en 1983, sino de volverlas a plantear en esta nueva ocasión. Las críticas arreciaron en primer lugar de su ex socios de la $\mathrm{AHI}$, quienes decían que el primer gobierno de Saavedra había hecho dejación, y no había aportado soluciones a los problemas de la ganadería y la agricultura, de manera particular en esa isla de El Hierro. En general, las fuerzas insularistas criticaron la falta de soluciones a los problemas específicos de su isla, si no habían entrado en el nuevo pacto de gobierno. De manera general la crítica se sostenía sobre el desacuerdo básico para el documento de adhesión a la CEE, y se repetían los argumentos dados en la sesión del día 22 de junio de 1985, excepto en el caso de los nuevos socios de gobierno (PCE,

\footnotetext{
${ }^{52}$ Ibídem. pág. 2667.
} 
Partido de la Revolución Canaria -PRC- y AM), que ahora no entraban en la apreciación a fondo sobre ese asunto, lo cual le valió la crítica del diputado Brito González, de la izquierda nacionalista, que señalaba, de manera irónica, que fueran los denostados "africanistas" de antes del 22 de junio los que le diesen nueva mayoría al gobierno. Decía el diputado de UPC: "A usted, que tanto atacaba al africanismo, al criollismo, al autodeterminismo de algunas fuerzas que votaron el espíritu y la letra del documento de la Comisión de Economía y Comercio del 22 de junio, le han salvado. África le ha salvado, señor candidato; los africanistas y criollistas de ayer, los autodeterministas han salido del fondo del infierno para sacarle a usted del atolladero político en el cual usted se había metido" ${ }^{23}$.

Desde el lado opuesto del mapa ideológico, el diputado de Coalición Convergencia Nacionalista Canaria (CCNC), Gregorio Toledo, acusaba al PSOE de haber pactado con una fuerza "marxista-leninista que preconiza la lucha de clases" en referencia al Partido de la Revolución Canaria (PRC) de Gonzalo Angulo y, por otro lado, extendía también la crítica al hecho de que Asamblea Majorera fuese una de las fuerzas integrantes del nuevo pacto, a la que criticaba por insularista, cuestión que era rebatida por AM, señalando que aunque fuesen de implantación insular no eran una fuerza insularista. CCN acusaba al candidato de no construir Canarias, "la región", pactando con fuerzas de ámbito insular, sin diferenciar, de manera interesada, entre insular e insularismo. Acusaba de frívolo el hecho de que los "majoreros" demandasen como nudo central de su programa la salida de la Legión de la isla, en la cual se había acantonado desde la partida española del Sahara Occidental.

Los majoreros replicaron al CCN que si bien ellos de manera orgullosa "no salían de su Isla", en cambio, Toledo no salía del paseo de la playa de Las Canteras, en alusión a la playa capitalina de Las Palmas de Gran Canaria. Cuando AM desgranó la razón de ser de su necesidad histórica, anotó el hecho del olvido histórico en que se encontraba su isla ante el "hegemonismo histórico de las islas centrales", y encontrándose en las antípodas del insularismo insolidario y mezquino, se reivindica como insular (no insularista) y justificaba su existencia por la necesidad de autorganización de un pueblo (el majorero) "ante la creciente y brutal militarización que

\footnotetext{
${ }^{53}$ Diario de sesiones, 16 de julio de 1985, nº 42, pág. 2696.
} 
sufre por la torpe y atropellada descolonización del Sahara" ${ }^{24}$. Abogaban por convertir Canarias en una plataforma de paz. AM señalaba que su filiación de izquierda y progresista la llevaba a apoyar con firmeza la ley de aguas propuesta por este gobierno, para "acabar con la especulación" y mantuvo el criterio de renegociar los aspecto negativos del tratado de adhesión con la CEE. Los majoreros querían una ley de cabildos que desde la defensa de la unidad de Canarias, dotase a esas instituciones de competencias necesarias para el buen gobierno insular, y también la creación de una hacienda canaria producto de una reforma en profundidad del REF.

El grupo de Izquierda Canaria, justificó su participación en el pacto de progreso aduciendo que con ello se podían impulsar políticas de avance progresista en una línea socialdemócrata, a la vez que trabajar en la dirección de la unidad política de Canarias. Los principales puntos del programa de gobierno incorporaban la ya mentada ley de aguas, una ley de las administraciones públicas, una ley de cabildos y otras medidas de corte social de interés para las mayorías sociales. La ruptura del bloque del grupo de izquierdas se había producido por cuanto uno de sus diputados de izquierda nacionalista no apoyaba el pacto de progreso, lo que llevó a una agria disputa en la sesión plenaria entre los miembros de este grupo. Fueron de hecho las interpelaciones entre estos diputados las más beligerantes durante el debate. Unos y otros se acusaron mutuamente de hacerle el juego al rival político, y de ocultar secretos inconfesables sobre pactos contranatura antes y después de las elecciones. A las acusaciones que hizo Angulo a Brito de haber pactado en secreto con la derecha de Manuel Hermoso (Agrupación Tinerfeña de Independientes -ATI-) en 1983, respondió Brito acusando a Angulo de haber dinamitado el Sindicato Obrero Canario y a la propia UPC, con el objetivo único de buscar "un lugar bajo el sol".

Por su parte, el tercer integrante del grupo de Izquierda Canaria, el representante del PCE, intervino para remarcar la necesidad del pacto de cara a afrontar los graves problemas del paro y otros de carácter institucional que ya hemos comentado. En relación a la CEE, se reafirmó en el protocolo 2 con mejoras a negociar en algunos aspectos referidos a los contingentes y los precios de referencia, los dos caballos de batalla de todo el asunto de entrada a la CEE.

\footnotetext{
${ }^{54}$ Ibídem. pág. 2698
} 
Las derechas criticaron tanto los aliados escogidos por el PSOE, como las propuestas de gobierno que pensaba llevar adelante. De los aliados dijo Fernandez (CDS) que los españoles debían de saber que el PSOE había pactado con la coalición de Sagaseta ${ }^{55}$ y con AM, que era conocida en España por su oposición a la legión, como si ello fuese el mayor de los pecados capitales. Fernández era tanto partidario de la permanencia en la OTAN como del mantenimiento de la legión en la isla. En cuanto a la crítica de la ley de cabildos que se quería llevar a cabo no era del agrado de la derecha, que prefería no unos cabildos jerarquizados bajo el poder de la Comunidad Autónoma, sino cabildos con más potencial de gobierno propio en la línea del insularismo histórico. Sobre la ley de aguas mantenían criterios diferentes acerca del alcance de la titularidad pública de las mismas, teniendo en cuenta las galerías ya puestas en explotación y las nuevas por ponerse. La posición del grupo popular a las críticas sobre el modelo de entrada en la CEE, y a las demás leyes propuestas para la segunda parte de la legislatura, fueron acompañadas de otro tipo de sentencias más banales, como la que ponía en duda que el socialismo "fuese la filosofía adecuada para resolver los problemas de Canarias (...) y menos creemos en los hombres que en estos momentos están representando a esa ideología" ${ }^{56}$. Las espadas quedaban en alto, pero ahora un cambio de orientación en el voto de una minoría de diputados (PCE-PRC-AM) lograba una mayoría suficiente para desatascar el problema de la integración canaria en la CEE. En consecuencia, el objetivo se había logrado y Canarias se adhería a las Comunidades Europeas por medio del protocolo 2, siendo de esta forma la única Comunidad Autónoma del estado que tenía un status diferente en Europa. Esta modalidad de adhesión se mantuvo vigente hasta que fue modificada a finales de 1989, ya con un nuevo gobierno autónomo capitaneado por las derechas.

La adhesión por medio del protocolo 2 en Europa no cubrió las expectativas que había generado al principio de su entrada en vigor, y aunque no fue una catástrofe para los agroexportadores tal y como estos presuponían, tampoco dio respuesta a los problemas de la economía canaria. En la valoración que hizo el expresidente Saavedra se decía que a pesar del trabajo realizado para alcanzar el reconocimiento de la

\footnotetext{
${ }^{55}$ Sergio MILLARES CANTERO, Fernando Sagaseta. La vida de un luchador irremediable, Las Palmas de Gran Canaria, Prensa Canaria, 1994.

${ }^{56}$ Diario 16 Julio, Ibídem. pág. 2731.
} 
especificidad canaria en Bruselas, las expectativas para el sector agrícola no se lograron. "Por mucho que España ejerciera el veto durante nueve meses a las concesiones que daba la CE a los países mediterráneos del Norte de África, las contrapartidas para Canarias fueron una pequeñez que no resolvía los grandes problemas de nuestras exportaciones agrícolas, sometidas a barreras comunitarias" ${ }^{27}$. Ello fue lo que aconsejó un cambió de posición del PSOE y del gobierno canario en relación a la CEE. Y este cambio se llevó a efecto en 1989 estando en el gobierno la coalición de las derechas (CDS-AP-AIC -Agrupaciones Independientes de Canarias-), aunque recibiendo también el respaldo del PSOE. El artículo 25.4 del acta de adhesión permitía esa posibilidad. "Este artículo se utilizó cuando a finales de 1989, el Parlamento canario se pronunció mayoritariamente, por un cambio en las relaciones de las islas con la CE y, en 1990, Fernández Ordoñez, en nombre del Gobierno de España, tras consultar a las instituciones canarias, inició el proceso de revisión del protocolo 2, como forma de Adhesión de Canarias" ${ }^{25}$.

\section{La coalición derechista y el camino hacia el POSEICAN}

El nuevo gobierno formado por el CDS, las AIC, AP y el apoyo parlamentario de $\mathrm{AHI}$, revertió el modelo de integración con el apoyo también del PSOE. En el nuevo pacto adujeron que al no haberse aprobado íntegramente el documento de 1983, sino el modificado de 1985, se había dejado fuera aspectos claves de las reivindicaciones canarias. Entre las principales razones que se dieron para dar por concluido el periodo del protocolo 2 estaba el hecho de que se creía que dicho protocolo generaba incertidumbre en el sector industrial, pesquero y el agroexportador al no haberse logrado meter a Canarias en el área aduanera común. Este asunto significaba un lastre para el sector industrial, y a ello se sumaba que los plataneros deberían renegociar su posición en relación al mercado peninsular de plátanos en 1996, e incluso tratar de ampliarlo al conjunto de la CEE, según sus pretensiones. Este sector tenía que competir en breve tiempo con los plátanos procedentes de los países ACP (África, Caribe, Pacífico), muchos de ellos antiguas colonias de varios países de la CEE, o bien

\footnotetext{
${ }^{57}$ Ibídem. pág. 18.

${ }^{58}$ Teresa NOREÑA SALTO, "Canarias..., op.cit. pág. 421.
} 
con los de área dólar, estos bajo el paraguas de las compañías exportadoras estadounidenses, lo cual dejaba en clara desventaja la producción canaria frente a esos colosos, que además producían en mejores ventajas competitivas salariales y estructurales. En el marco de la CEE los principales productores de plátanos eran los DOM (Departamentos de ultramar franceses) y Canarias, pero su producción apenas alcanzaba el $30 \%$ del mercado comunitario.

Desde el comienzo del año 1989 los eurodiputados canarios impulsaron el denominado Informe Griffith, en el cual se recogía la reivindicación de mejora del protocolo 2 en la línea de las reivindicaciones manifestadas en los años precedentes desde Canarias. No hubo una respuesta tácita a este documento, pero la Comisión Europea creó el Grupo Interservicios para analizar los regímenes excepcionales existentes en el seno de la CEE. De los trabajos del grupo surgió una propuesta sobre los departamentos franceses de ultramar (POSEIDOM), al que los canarios prestaron atención, dado que debido a las similitudes entre estos territorios y Canarias podría ser beneficioso la aplicación a ésta de algunos de los puntos recogidos en el referido documento. Interés especial suscitaron las políticas de ayuda a las industrias de transformación y comercialización de productos agrícolas, a la subvención al transporte, así como a las políticas ganaderas, que se veían reforzadas con insumos y promoción de los intercambios con los países vecinos.

En el informe del gobierno se señalaba, no obstante, que existían diferencias de calado entre estos territorios y Canarias, porque aquéllos ya estaban plenamente integrados en las políticas comunitarias y porque el peso del sector público en los DOM era muy superior al canario, dado que allí representaba el $32 \%$ del empleo y el $40 \%$ del PIB insular, procedente de las transferencias del gobierno francés ${ }^{59}$. La importancia del POSEIDOM estribaba en que era el modelo máximo de reconocimiento de especificidades que se había aprobado hasta entonces en la CEE. El gobierno opinaba que lo que tenía que dirimir la cámara autonómica era hasta dónde debía de llegar el

\footnotetext{
${ }^{59}$ Diario de sesiones 21 de diciembre, $n^{\circ} 43$, de 1989. Justin DANIEL, "The construction of dependency: Economy and politics in the French Antilles" págs. 61-80. Fred CONSTANT, "The French Antilles in the 1990s: Between european unification and political territorialisation” págs. 80-95. Ambos artículos en Aarón GAMALIEL RAMOS y Angel ISRAEL RIVERA, Islands at the crossroads. Politics in the NonIndependent Caribbean, lan Randle Publishers, Kingston, 2001.
} 
nivel de integración de las Islas, partiendo de la premisa de que la plena integración no era una opción a elegir.

El escenario mundial, y en particular en Europa, estaba entonces en pleno proceso de transformación, porque sucedían acontecimientos históricos tales como la caída del bloque oriental o la entrada en vigor del Acta Única Europea, así como la posible ampliación al este de la propia CEE, o incluso más allá de Europa, si nos atenemos a las demandas de integración realizadas por Marruecos y Turquía. Paralelamente la Ronda Uruguay, antecesora de la Organización Mundial de Comercio, abogaba por la apertura definitiva del mercado mundial para los productos agrarios. Se estaban sentado las bases del modelo de globalización neoliberal, en la que sería más complicado establecer pautas de protección para la producción y exportación de los productos. Así que ahora lo que el gobierno de Canarias pretendía era modificar los términos de la relación con la CEE, que ya no pasaba por quedarse a medio entrar y negociar fórmulas específicas para determinados productos y una fiscalidad diferenciada, sino en entrar del todo pero manteniendo cierta exenciones y particularidades. Se invertía así la lógica del proceso negociador de 1985.

Las izquierdas parlamentarias fueron críticas con la propuesta del gobierno. Los diputados de Izquierda Canaria Unida (ICU), Asamblea Nacionalista Canaria (ANC) y Asamblea Majorera (AM) (2, 2 y 3 parlamentarios respectivamente) manifestaron reservas importantes para no votar a favor de lo que proponía el gobierno de Olarte, en cuanto a la modificación del status canario en la CEE. Los nacionalistas de izquierdas de ANC, cuyo portavoz era el poeta Pedro Lezcano, se mostraban partidarios de rechazar cualquier propuesta que conllevase la integración total, aunque igualmente evidenciaban desacuerdo con el protocolo 2, por la cuestión de los contingentes y los precios de referencia. Los nacionalistas abogaban por negociar un nuevo REF, así como una política tendente a usar en positivo la renta de situación, avalada por la consecución de un estatuto de neutralidad que hiciese posible que Canarias se relacionase con los pueblos vecinos desde un principio de reciprocidad, y de fomento de las relaciones culturales y comerciales. Igual que los demás grupos de las izquierdas, los nacionalistas eran partidarios de que cualquier modelo de relación con la CEE terminase siendo avalado por un referéndum. Los nacionalistas de izquierda no abandonaban la idea de que si la negociación no satisfacía las demandas canarias, se 
plantease la desvinculación total de la CEE. Por su parte, los también nacionalistas de AM postulaban la necesidad de mejorar el protocolo 2 , y entendían que lo primordial era la renegociación de los puntos conflictivos que no quedaron resueltos en 1985, sobre todo los que tenían que ver con la agricultura y la pesca. Ello conllevaba una modificación del REF, entendiendo que debía ser la piedra angular de la posición diferenciada de Canarias en Europa. Los "majoreros" eran críticos y contrarios a que se aplicase en Canarias el principio de la libre circulación de trabajadores comunitarios, porque aducían que haría mucho daño a la mano de obra canaria.

Los comunistas de ICU (versión canaria de IU) también eran contrarios a respaldar el documento presentado al Parlamento por parte del gobierno canario. Los comunistas combinaban la declaración de fe europeista, una Europa desde los Urales hasta el Atlántico, seguramente en la estela de la propuesta de la casa común europea de la que habló Gorbachov unos meses antes en la asamblea del Consejo de Europa en Estrasburgo, con una lectura realista del espacio geopolítico en que se encontraban las islas, a caballo entre tres continentes. Esa posición tricontinental debía ser usaba para promover la cooperación y el encuentro entre Europa, América Latina y África. Para que fuese factible pasaba porque Canarias tuviese reconocido un estatuto especial en la CEE, que respetase el acervo histórico insular y que a la vez facilitase el papel de las islas como lugar de encuentro y cooperación tricontinental. La posición que razonaba ICU criticaba el documento del gobierno, porque entendía que se parecía más a un documento de una "Cámara de Comercio" que a un documento de un Parlamento autonómico ${ }^{60}$. ICU proponía que la modificación del protocolo 2 sirviese para incorporar a Canarias a la PAC (Política Agraria Común) y a la política pesquera común, pero ello manteniendo el régimen especial canario, lo que denominaban el acervo histórico. E incluso planteaban ampliar dicho acervo con la creación de una hacienda canaria nacida de la modificación del REF. Canarias, en la negociación del cambio de status, debía hacer frente al desafío subiendo el nivel de cualificación de la población trabajadora, por medio de planes de formación profesional respaldados con fondos de la CEE.

\footnotetext{
${ }^{60}$ Diario de sesiones, Ibídem. pág. 2968.
} 
La postura del PSOE, que era entonces el principal partido de la Cámara con 21 diputados y un $27 \%$ del voto popular, era la de respaldar la posición negociadora del gobierno sin renunciar a defender lo logrado hasta entonces con la aprobación del protocolo 2, pero señalando que, si aquél había quedado superado, no invalidaba el hecho de que en su gestación se había intentado lograr el reconocimiento de las particularidades canarias, y que siempre había tenido presente que el ejercicio de la negociación debía ser permanente entre Canarias y la CEE, dado que el status canario así lo exigía. "No hay que enterrar a Bravo Murillo ${ }^{61}$, sino hacer que hayan otros Bravo Murillo" fue la idea que expresaba que las particularidades canarias debían ser renegociadas siempre que nuevas condiciones así lo aconsejasen. La actitud del PSOE fue respaldar, conjuntamente con los grupos de la derecha que sostenían al gobierno, la modificación del protocolo de adhesión de Canarias a la CEE. Una mayoría de votos (54 sobre 60 ) a favor sostuvo la posición del gobierno, mientras cinco votaban en contra y se producía una abstención.

El documento solicitaba el cambio de status pero manteniendo las medidas necesarias para el reconocimiento de la lejanía y la insularidad, protección del sector agrícola, del industrial, mantenimiento de las importaciones de países no comunitarios y aplicación de un periodo transitorio para la ejecución del nuevo status y el mantenimiento del REF. Las propuestas canarias habían estado influenciadas por el caso del estatuto del POSEIDOM, y fruto de la nueva situación se aprobó a finales de 1990 (diciembre) por parte de la Comisión de las Comunidades Europeas, la aceptación de la modificación del estatuto canario en relación a la política agraria, pesquera, la unión aduanera, el régimen fiscal y el establecimiento de un plazo de aplicación de estas nuevas medidas. Unos meses más tardes (febrero) se aprobaba un documento canario de nuevas relaciones con la CEE denominado POSEICAN (Programa de Opciones Específicas por la Lejanía y la Insularidad de las Islas Canarias).

El nuevo estatuto canario en la CEE recogía la ideas fundamentales del grupo interservicios, que consistían en reconocer los problemas que generaban las condiciones archipielágicas, la fragmentación del territorio, la lejanía a Europa y la

\footnotetext{
${ }^{61}$ Presidente del Consejo de Ministros en 1852, bajo cuyo mandato se aprobó la primera ley de puertas francos para Canarias.
} 
existencia de la aplicación de medidas excepcionales que las "metrópolis" siempre han dispensado a estos territorios ${ }^{62}$. EI POSEICAN se había propuesto como objetivos la inserción de Canarias con un marco adecuado a las características de las islas, incluyendo su participación en el mercado único. Canarias pasó a ser región ultraperiférica de la CEE junto con las otras regiones de ultramar de Francia y Portugal, y se definieron prioridades en los terrenos del transporte, la fiscalidad, las ayudas sociales, la investigación y desarrollo, y en la protección del medio ambiente ${ }^{63}$. También se aprobó un Régimen Específico de Abastecimiento (REA), y se impulsaron medidas para la creación de zonas francas con baja tributación en lo que se conoce como Zona Especial Canaria (ZEC). Las particularidades canarias quedaron finalmente reconocidas en el Tratado de Maastricht en 1992, en cuya Declaración relativa a las regiones ultraperiféricas de la Comunidad, se dice lo siguiente: "La Conferencia reconoce que las regiones ultraperiféricas (departamentos franceses de Ultramar, Azores, Madeira y las Islas Canarias) padecen un importante atraso estructural agravado por diversos fenómenos (gran lejanía, insularidad, escasa superficie, relieve y clima difíciles, dependencia económica respecto de algunos productos) cuya constancia y acumulación perjudican gravemente a su desarrollo económico y social.

Considera que, si las disposiciones del Tratado constitutivo de la Comunidad Europea y del Derecho derivado se aplican de pleno derecho a las regiones ultraperiféricas, ello no obsta para que se adopten disposiciones específicas en su favor mientras exista una necesidad objetiva de adoptar tales disposiciones con vistas a un desarrollo económico y social de estas regiones. Estas disposiciones deberán tener por objetivo a la vez la realización del mercado interior y el reconocimiento de la realidad regional, con vistas a hacer posible que las regiones ultraperiféricas alcancen el nivel económico y social medio de la Comunidad"64.

Concluía de esta manera una larga década de propuestas sobre la mejor conveniencia para la inserción en la CEE -ahora UE-. Canarias era el único territorio del Estado español que tenía personalidad propia en el seno de las comunidades

\footnotetext{
${ }^{62}$ Giuseppe CIAVARINI AZZI, "EI modelo de integración específico de las regiones ultraperiféricas de la Comunidad Europea" en Canarias en la Comunidad Europea, Fundación Pedro García Cabrera, 1994.

${ }^{63}$ Teresa NOREÑA SALTO, "Canarias..., op. cit.

${ }^{64}$ Tratado de la Unión Europea, 1992.
} 
europeas, a pesar de tener un nacionalismo político menos desarrollado que otras naciones del Estado, que en cambio sí tenían un mayor reconocimiento en la estructura política española como realidad diferenciada (Cataluña, Euskadi y Galicia). El hecho insular, el atraso económico y social, y la ubicación geográfica son razones fundamentales para entender la disposición europea a dar respuesta a las demandas canarias.

\section{Conclusión}

La adhesión de Canarias a la CEE estuvo jalonada de un largo debate entre los sectores económicos, los partidos políticos y los intelectuales. Para algunos la perspectiva que se abría entrañaba riesgos para el futuro inmediato, y no se sentían tranquilizados por la marcha de las negociaciones que capitaneaba el gobierno central. Para otros, el asunto tendría que solucionarse sin poner en cuestión el status quo de Canarias en el seno del Estado español y de Europa. Para unos terceros, lo primordial consistía en mantener un nivel alto de capacidad política de las instituciones del archipiélago, que permitiesen elaborar políticas soberanas en el contexto de la tricontinentalidad de la islas.

Los principales agentes económicos, es decir, los que tenían de facto capacidad de lobby sobre el gobierno autonómico y central, opinaban que con la entrada de Canarias en la CEE se debería de respetar lo fundamental del REF. Canarias estaría en Europa de manera similar a como estaba en España. Esta fue la principal hipótesis para la negociación en la que también se reconocía la mayoría parlamentaria en la Cámara autonómica. Primero, se intentó con un protocolo especial con el que Canarias se quedaría fuera de ciertas políticas comunitarias, aplicándosele determinadas cláusulas para protegerla de los estados terceros. Después, esta opción se cambió por la de la entrada completa, pero permitiendo determinadas salvedades, lográndose con ella la promulgación del POSEICAN, que desde Maastricht, marcó las relaciones de Canarias con la UE.

Por otra parte, las organizaciones del nacionalismo de izquierda fueron partidarias de mantenerse fuera de la CEE, en el supuesto de que no se lograsen 
todas las demandas de las Islas, y que, en cualquier caso, y a esta petición se sumaban los comunistas, cualquier vía debía ser refrendada por la ciudadanía por medio de las urnas. Estas posiciones, que fueron minoritarias en el Parlamento, ayudaron a agitar el debate sobre la integración sacándolo del mero asunto fiscal y económico e introduciendo los aspectos políticos de la integración.

La dimensión geográfica del archipiélago se transformaba en los asuntos de calado internacional en una de orden geopolítico ${ }^{65}$. Si además de la entrada en la CEE se estaba negociando también si España debía permanecer en la OTAN, y en tal caso qué papel se le reservaba a Canarias en dicha alianza, el escenario se complicaba, porque si para la CEE la mayoría social y política estaba por probar la integración en cualquiera de sus modalidades, para el tema OTAN, la mayoría social y política era contraria a la permanencia, tal y como quedó reflejado en el referéndum de marzo de 1986 en el que la población del archipiélago votó por la no permanencia en la alianza militar.

El asunto canario en Europa se convirtió en la única excepción al respecto entre los distintos territorios, nacionalidades y autonomías que forman parte del Estado español. Canarias se desveló en el proceso de negociación para la adhesión de España a las Comunidades Europeas, como el único territorio realmente diferenciado, independientemente de la influencia del nacionalismo político en las islas. Si bien el poder de éste no alcanzaba el nivel y la fuerza que sí tenía en otros territorios, su existencia, aunque minoritaria, más las coordenadas geopolíticas, hicieron de Canarias un territorio realmente excepcional en el proceso de adhesión española a la CEE.

${ }^{65}$ Domingo GARÍ, Geopolítica, nacionalismo y tricontinentalidad, La Laguna, Sociedad Latina de Comunicación Social, 2015. 


\section{Siglas}

ACP- África, Caribe, Pacífico

AGI- Agrupación Gomera de Independientes

AHI- Agrupación Herreña de Independientes

AIC- Agrupaciones Independientes de Canarias

AM- Asamblea Majorera

ANC- Asamblea Nacionalista Canaria

ATI- Agrupación Tinerfeña de Independientes

CCNC- Coalición Convergencia Nacionalista Canaria

CECAPYME- Confederación Canaria de la Pequeña y Mediana Empresa

COREICA- Confederación Regional de Empresarios de las Islas Canarias

FEDECO- Federación de Desarrollo Empresarial y Comercial de Canarias

ICU- Izquierda Canaria Unida

PAC- Política Agraria Común

PRC- Partido de la Revolución Canaria

REA- Régimen Específico de Abastecimiento

REF- Régimen Económico y Fiscal

SODICAN- Sociedad de Desarrollo Industrial de Canarias

UNIPYME- Unión de la Pequeña y Mediana Empresa

UPC-AC- Unión del Pueblo Canario-Asamblea Canaria

ZEC- Zona Especial Canaria 